etretinate $\left(\right.$ Tigason $\left.^{\circledR}\right)$. We have therefore examined 19 children and adolescents who have been continuously treated with etretinate for several years (median duration of treatment 5 years). Their overall mean daily dose ranged from 0.4 to $1 \mathrm{mg} / \mathrm{kg}$ (median $0.8 \mathrm{mg} / \mathrm{kg}$ ).

All subjects received musculoskeletal assessment and a ${ }^{99 \mathrm{~m}}$ technetium methylene diphosphonate ( $\left.{ }^{99 \mathrm{~m}} \mathrm{~T}_{\mathrm{c}} \mathrm{MDP}\right)$ whole body bone scan, which results in a lower total radiation dose than a skeletal survey, and is more sensitive. Bone scans identify sites of abnormal turnover of bone earlier than plain radiographs, and are valuable in the early assessment of abnormalities of the growth plate, provided high resolution collimation is used.

These studies revealed no evidence of significant bony abnormality in any patient.

We therefore believe that long-term etretinate therapy can probably be given with a low risk of musculoskeletal toxicity if certain precautions are taken, particularly use of low doses, early investigation of musculoskeletal symptoms and regular ${ }^{99 \mathrm{~m}} \mathrm{Tc}$ MDP bone scans.

\title{
Histological and immunocytological changes in psoriasis after 7 days of cyclosporin therapy
}

\section{J.T.Headington, K.D.CoOper, C.N.Elils and J.Voorhees}

Department of Dermatology, University of Michigan, Ann Arbor, Michigan, U.S.A.

In a double-blind trial, 2 I patients were randomly assigned to receive oral cyclosporin or a vehicle control. Patients were treated for 4 weeks. Skin biopsies were taken before treatment and after 3 and 7 days. Epidermal thickness was measured by optical micrometer, and mitoses per high power field (HPF) were counted in lesional epidermis. Superficial perivascular mononuclear cell infiltrates, neutrophilic exudates and intraepidermal lymphocytosis were evaluated semi-quantitatively. Using single- and double-marker immunofluorescence techniques, the ratio of monoclonal antibody-defined leukocyte subsets to total leukocytes was also quantitatively determined.

In patients receiving cyclosporin, epidermal thickness decreased by $32 \%$ compared with patients receiving only vehicle $(P=0.002)$. The average number of mitoses per HPF in lesional epidermis decreased by $71 \%$ by the end of 3 days of therapy. At 7 days, perivascular mononuclear cells decreased and the stratum corneum generally normalized.

HLA-DR (Ia)-positive intraepidermal leukocytes found in psoriatic lesions before treatment or present in vehicle-treated lesions disappeared from the epidermis after 7 days of oral cyclosporin. Intradermal monocytes, $T$ cells and activated $T$ cells in the dermis decreased after 7 days of cyclosporin treatment in parallel with light microscopic findings.

These findings suggest that psoriasis may have an immunological basis mediated by activated $\mathrm{T}$ cells and/or other immune cells.

\section{Fish oil in psoriasis-a double-blind randomized placebo-controlled trial}

\author{
S.B.BitTineR, W.F.G.TUCKER AND S.S.BLEEHEN
}

Department of Dermatology, Royal Hallamshire Hospital, Sheffield

Recent uncontrolled work has suggested that dietary supplementation with fish oils high in 
This document is a scanned copy of a printed document. No warranty is given about the accuracy of the copy. Users should refer to the original published version of the material. 